Original Article (short paper)

\title{
Differences in physical activity levels of school domains between high- and low-active adolescents
}

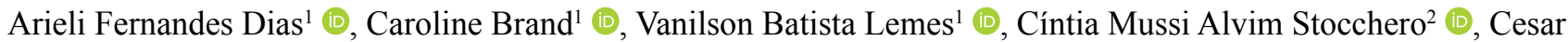

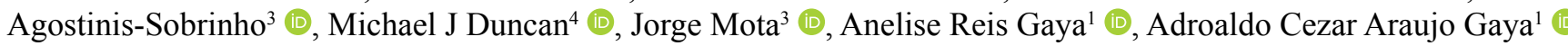 \\ ${ }^{1}$ Federal University of Rio Grande do Sul, UFRGS, Project Sport Brazil, PROESP-Br, Post graduation program in Human \\ Movement Sciences. School of Physical Education, Physiotherapy and Dance, Porto Alegre, RS, Brazil, ${ }^{2}$ Federal Institute of \\ Education, Science and Tecnology of Rio Grande do Sul, IFRS, RS, Porto Alegre, RS, Brazil; ${ }^{3}$ University of Porto, Research \\ Center on Physical Activity, Health and Leisure. Faculty of Sport, Porto, Portugal; ${ }^{4}$ Coventry University, Biomolecular \\ and Sports Sciences. Faculty of Health and Life Sciences, United Kingdom of Great Britain and Northern Ireland.
}

\begin{abstract}
Aim: To compare high active (HA) and low active (LA) adolescent's physical activity (PA) levels in three different domains: commuting to school, physical education (PE) class and recess time at school. Method: This is a cross-sectional study, with a quantitative approach and random sample of 176 (105 girls) adolescents aged 14 - 18 years old from 10 urban public high schools in southern from Brazil. PA levels were measured using a pedometer. The average number of steps was recorded on the way to school, during PE classes and during school recess time. Participants were classified as HA and LA according to Tudor-Locke's cut-off points. Data were analyzed using descriptive statistics and One-Way ANOVA stratified by sex. Results: Data showed differences of mean values between school commuting PA for girls (LA: 1057.60; HA: 1624.54; $\Delta$ : 566.94; $\mathrm{p}<0.001$ ), during PE class (LA: 1401.75, HA: 1701.10; $\Delta$ : 308.53; $\mathrm{p}<0.05$ ) and in recess time (LA: 443.09, HA: 611.98; $\Delta: 168.89 ; \mathrm{p}=0.001$ ), whereas for boys, differences only found between the mean values of PA during PE class (LA: 1787.91, HA: 2511.20; $\Delta: 723.29 ; \mathrm{p}<0.01$ ). Conclusion: HA girls are consistently more active in each domain analyzed compared to LA counterparts, while for boys PE class was the domain that differentiated the HA vs. LA adolescents. This study highlights some potential settings to be included in the policies focused in enhance PA levels among adolescents namely in the context of school PE.
\end{abstract}

Keywords: youth; health; physical education; active commuting.

\section{Introduction}

Low levels of physical activity (PA) are associated with increasing risk of several chronic diseases and premature mortality ${ }^{1,2}$. Therefore, the detection of insufficient levels of physical activity seems to be essential for identifying children and adolescents with increased risk of developing health problems early in life, such as metabolic syndrome, diabetes, obesity and other cardiometabolic risk factors ${ }^{3,4}$.

There are several determinants associated with regular engagement in PA, including parental support, school environment, active commuting, leisure activity and available places for PA practice ${ }^{5,6}$. For evidence-based planning of public health interventions it is important to understand these determinants of PA behavior as well as the context in which they occur $^{7}$. One of the more important settings for interventions to enhance PA levels is the school, particularly through developing and applying programs related to health promotion and also curriculum physical education (PE) classes ${ }^{8}$, active recess time and even commuting to school. However, the contribution of these different domains to total daily PA is not well established. This is especially the case for high active (HA) and low active (LA) adolescents. Understanding if there are differences in the use of different domains for PA between HA and LA adolescents is an important first step for effective targeting of interventions to enhance PA and improve health status.

Thus, we hypothesized that HA adolescents are more active in commuting to school, PE class and recess time at school. In addition, we emphasize that the present study add new information, since no investigation has been developed, regarding difference between PA levels in these contexts among Brazilian adolescents. The purpose of the current study was to compare HA and LA adolescent's PA levels in three different domains: commuting to school, PE class and recess time at school.

\section{Methods}

\section{Participants}

This study uses a cross-sectional, quantitative, study design. The population of the study comprises adolescents drawn from 15 public high schools from Passo Fundo, RS, Brazil. Approximately 4.599 students were enrolled in the public high school education network, according to the $7^{\text {th }}$ Regional Education Coordinator. All data were collected between August and December 2014.

The sample size was calculated considering a sampling error of $5 \%$, a proportion of $10 \%$ and a significance level of $95 \%$. 
The minimum sample size was 134 students identified by the following equation: $\left(n=Z \alpha \cdot p \cdot q \cdot N / e^{2} \cdot(N-1)+Z \alpha^{2} \cdot \mathrm{p} \cdot \mathrm{q}\right)^{9}$. Where: $\mathrm{N}=$ minimum sample size to calculate; $\mathrm{Z} \alpha=$ significance level measured in unit of standard deviation; $p=$ proportion of subjects in the population; $\mathrm{q}=100-\mathrm{p} ; \mathrm{N}=$ population size; and $\mathrm{e}=$ sampling error.

In order to account for possible sample drop out due to measurement errors and non-compliance with inclusion criteria, an increase in sample size of $30 \%$ was employed. Thus, 200 adolescents were invited and 176 accepted to participate in the study. The sample selection occurred in three phases. First, the city was geographically divided into five regions (north, south, east, west and center). Then two schools (from the 15 total state schools) were randomly selected from each region, completing 10 schools evaluated. In the third phase, one high school class was randomly drawn in each of the selected schools. All the students in each class were invited to participate in the study, however, only participated the ones that signed the free and informed consent. These criteria were adopted for random and well-distributed sample purposes.

The inclusion criteria for participants were: 1) to be enrolled in public high schools in Passo Fundo City; 2) age ranged between 14 until 18 years old; and, 3) showed the free and informed consent form signed by parents/guardians as well assent indicating willingness to participate. Participants who presented any physical and/or cognitive limitation that could compromise the outcome of the study were excluded from participation. The Human Ethics Research Committee of the Federal University of Rio Grande do Sul, under number 888.090, approved the study.

\section{Procedures}

PA level was evaluated using pedometer with the number of steps accumulated during the following four periods being used for subsequent analysis: during PE class, during school recess period, during commuting to school and total daily PA. PA was assessed using a pedometer (Yamax ${ }^{\circledR}$ Digi-Walker CW 700, Tokyo, Japan) worn for three consecutive days (Monday to Wednesday). During PE classes, students wore a pedometer within one class, except in schools that offered two weekly periods of PE classes. In these instances the pedometer was worn in both classes and the average number of steps was considered for analysis. The average number of steps accrued during school recess, commuting to school and for total daily PA, during the three days was used for subsequent analysis. Pedometer derived daily step-counts have been shown to be a convenient and reliable measure of PA behavior among children and adolescents ${ }^{10,11}$. Furthermore, systematic review data identify that pedometers can be effectively employed to identify the level of PA engaged in different contexts and time points ${ }^{12}$.

For data collection, the following procedures were followed: students were informed about the location the of pedometer (waist); the equipment was attached using an elastic belt; students received a logbook, where they recorded the number of steps on their pedometer at certain times, such as: when they left home to go to school, when they arrived at school, beginning and end of PE class and school recess, and when they returned home or work; and a researcher was present at school in all activity shifts to solve any problems and remind them to take notes of their steps in the logbook. These data were collected in the spring of 2014.

Among the 176 adolescents, 114 provided recorded complete data for number of steps during PE class, 161 for recess time and 162 for commuting to school. Some sample losses occurred due to recording errors in pedometers and also due to students' absence on data collection days.

\section{Statistical analysis}

A sample descriptive statistical analysis characteristic was presented, through absolute and relative frequencies stratified by gender according to these variables: age in years; city region; PA level. The students were classified in HA or LA according steps number recommendation, using cut-off points proposed by Tudor-Locke ${ }^{13}$. The mean variance of PA level (steps-number) was compared between the two groups (HA x LA). The number of steps accrued during commuting to school, $\mathrm{PE}$ and in recess time were considered as dependent variables. The One-Way ANOVA test was performed for each sex. Inferential analysis was conducted with statistical significance set at $\mathrm{P}=.05$. eta ${ }^{2}$ was calculated as a measure of Effect Size. All data was analyzed in SPSS for Windows software version 22.0 (IBM Corp, Armonk, New York, USA).

\section{Results}

A total of 176 students ( 71 boys and 105 girls) aged 14 to 18 years (mean: 15.83 standard deviation: 0.85 ) were evaluated. Approximately $65 \%$ of adolescents were classified as LA, $64 \%$ girls and $65 \%$ boys (Table 1 ).

Table 1. Characteristics of participants stratified by sex.

\begin{tabular}{lccc}
\hline & $\begin{array}{c}\text { Male (n=71) } \\
\mathbf{n}(\mathbf{\%})\end{array}$ & $\begin{array}{c}\text { Female (n=105) } \\
\mathbf{n}(\mathbf{\%})\end{array}$ & $\begin{array}{c}\text { Total (n=176) } \\
\mathbf{n}(\mathbf{\%})\end{array}$ \\
\hline Age group (years) & & & \\
14 & $2(2.8)$ & $4(3.8)$ & $6(3.4)$ \\
15 & $21(29.6)$ & $38(36.2)$ & $59(33.5)$ \\
16 & $29(40.8)$ & $45(42.9)$ & $74(42.0)$ \\
17 & $17(23.9)$ & $16(15.2)$ & $33(18.8)$ \\
18 & $2(2.8)$ & $2(1.9)$ & $4(2.3)$ \\
Region & & & \\
Downtown & $18(25.4)$ & $14(13.3)$ & $32(18.2)$ \\
Northern & $17(23.9)$ & $23(21.9)$ & $40(22.7)$ \\
Southern & $11(15.5)$ & $26(24.8)$ & $37(21.0)$ \\
Eastern & $13(18.3)$ & $20(19.0)$ & $33(18.8)$ \\
Western & $12(16.9)$ & $22(21.0)$ & $34(19.3)$ \\
Level of PA* & & & \\
High active & $24(34.8)$ & $38(36.2)$ & $62(35.6)$ \\
Low active & $45(65.2)$ & $67(63.8)$ & $112(64.4)$ \\
\hline
\end{tabular}

n: absolute sample value; $\%$ : proportional sample value. *PA: Physical Activity (male $n=69$; total $n=174$ ), through Tudor-Locke cut-off points. 
Table 2 shows the results for HA and LA boys in relation to commuting to school, PE class and recess time. There was a difference between PA accrued during PE classes, equivalent to a difference of $11 \%$ between HA and LA boys PE. No differences were found either for commuting or recess time.

Table 3 shows PA for HA and LA girls according to the different domains studied. HA girls where significantly more active in each domain analyzed. Commuting to school was the domain which showed the greatest differences in PA between LA and HA girls.

Additionally, considering all adolescents in the analysis, there was difference between HA and LA in commuting to school (LA: 1146.84 , HA: $1581.49 ; \Delta: 434.65 ; \mathrm{p}<0.001$ ), recess time (LA: 503.42, HA: 672.80; $\Delta: 269.38 ; \mathrm{p}=0.002$ ) and PE class (LA: 1589.52, HA: 2050.57; $\Delta: 461.05 ; \mathrm{p}=0.006$ ).

Table 2. Step counts of high active and low active adolescent boys.

\begin{tabular}{|c|c|c|c|c|c|c|}
\hline & \multicolumn{6}{|c|}{ Boys } \\
\hline & \multirow{2}{*}{$\begin{array}{l}\text { Low Active } \\
\text { Mean (sd) }\end{array}$} & \multirow{2}{*}{$\begin{array}{c}\text { High Active } \\
\text { Mean (sd) }\end{array}$} & \multicolumn{4}{|c|}{ Low Active x High Active } \\
\hline & & & $\Delta$ & $\mathbf{F}$ & Eta $^{2}$ & $\mathbf{p}$ \\
\hline Commuting & $1286.14(588.20)$ & $1513.01(853.90)$ & 226.87 & 1.54 & 0.02 & 0.21 \\
\hline PE Class & $1787.91(769.50)$ & $2511.20(1307.32)$ & 723.29 & 6.40 & 0.11 & 0.01 \\
\hline Recess & 587.07 (491.49) & $760.05(326.49)$ & 172.98 & 2.96 & 0.04 & 0.09 \\
\hline
\end{tabular}

PE class: Physical Education Class; sd: standard deviation.

Table 3. Steps count of high active and low active adolescent girls.

\begin{tabular}{|c|c|c|c|c|c|c|}
\hline & \multicolumn{6}{|c|}{ Girls } \\
\hline & \multirow{2}{*}{$\begin{array}{l}\text { Low Active } \\
\text { Mean (sd) }\end{array}$} & \multirow{2}{*}{$\begin{array}{l}\text { High Active } \\
\text { Mean (sd) }\end{array}$} & \multicolumn{4}{|c|}{ Low Active x High Active } \\
\hline & & & $\Delta$ & $\mathbf{F}$ & Eta $^{2}$ & $\mathbf{p}$ \\
\hline Commuting & $1057.60(522.82)$ & $1624.54(638.95)$ & 566.94 & 22.68 & 0.19 & 0.001 \\
\hline PE Class & $1401.57(526.59)$ & $1710.10(676.95)$ & 308.53 & 3.95 & 0.06 & 0.05 \\
\hline Recess & $443.09(203.06)$ & $611.98(322.02)$ & 168.89 & 9.70 & 0.09 & 0.001 \\
\hline
\end{tabular}

PE class: Physical Education Class; sd: standard deviation.

\section{Discussion}

The current study sought to examine differences in PA between high active and low active adolescents in three different but key settings for accruing PA for health benefit. To the best of our knowledge this is the first study addressing the different levels of PA in different settings and domains in Brazilian youth. Our results identified that: I) $65 \%$ of adolescents did not achieve the recommended steps/day threshold for health; II) HA girls were significantly more active in all the domains analyzed while HA boys only were significantly more active during PE at school. Also for all adolescents, there was difference between HA and LA in commuting to school, recess time and PE class

In regard to the recommended levels of PA, our data is in agreement with several other reports. Indeed, several studies have shown that a high prevalence of adolescents do not reach PA recommendations evaluated either by questionnaires, pedometers or accelerometers ${ }^{14,15}$. Within the Brazilian context, our findings show that $64.4 \%$ of southern Brazilian adolescents did not achieve the recommended number of steps/day for health as suggested by Tudor-Locke et $\mathrm{al}^{13}$. This outcome is in agreement with a study conducted in southeast of Brazil, using the same approach ${ }^{16}$. The aforementioned study reported that $74.1 \%$ of their sample did achieve the recommended steps/ day for health ${ }^{16}$. As such the low level of PA found among our participants is not unusual but also emphases the need to understand the amount of PA accrued among different school contexts. The level of PA among Brazilian adolescents in the current study is congruent with other studies around the world ${ }^{12,13}$. Such results also highlights the necessity of approaches aimed to increase PA in the different contexts of an adolescent's day.

Active commuting as a domain of PA appears to be one important and promising strategy for increasing PA levels and improving adolescent health ${ }^{17-19}$. Our data identified that HA girls were significantly more active than their LA counterparts; while in boys the difference was not statistically significant. Some studies have demonstrated associations between active commuting to school with a favorable body composition, improvement in the cardiorespiratory and muscular condition, in addition to increased levels of $\mathrm{PA}^{20,21}$. However, these studies did not examine whether the level of PA during active commuting differed between HA and LA adolescents. Furthermore, a study conducted in a sample of Colombian children and adolescents indicated that girls who usually go cycling to school showed a lower association with incidence of metabolic syndrome and better physical fitness, when compared to those who travelled using passive transport ${ }^{22}$. Our results are also congruent with a systematic review of 68 studies conducted by Larouche, Saunders, Faulkner, Colley, Tremblay ${ }^{23}$ who found that commuting to and from school 
among adolescents should be promoted to increase PA levels in children and adolescents and that cycling to/ from school is associated with increased cardiovascular fitness.

Given the fact that girls usually have lower levels of daily PA compared to boys ${ }^{15}$, the results of our study indicate that commuting to school is an important domain, contributing for PA levels. In fact, our data showed that physical activity during commuting to school has contributed for increment of physical activity in HA girls compared to LA. Thus, health promotion actions should consider some factors related to environment, such availability of bicycle path, walking track and safety of neighborhood to increase PA levels of adolescents.

An important outcome from our study was the fact that there were differences in PA between LA and HA in both boys and girls in PE class. However, for boys this was the only domain where significant differences in PA were observed between HA and LA adolescents. This finding may be because competition and sports are preferences and these kind of PA is commonly offered in PE classes in Brazil ${ }^{24}$. Adolescents might also have greater motivation to participate in PA during PE which might translate to higher PA than their low active peers, despite the fact that the PE lessons are the same. Such motivational differences have been demonstrated previously in the context of PE classes ${ }^{25}$. In the context of school PA and also from a public health perspective the results of the present study are worthy of comment. Indeed, PE classes seem to play an important role on overall human development but specifically in enhancing the PA levels in adolescents ${ }^{26}$. The importance of enjoyment in PE classes has been described, indicating that nearly $37 \%$ of boys and $61 \%$ of girls met the recommended steps/day guidelines when PE was offere ${ }^{27}$. In addition, during PE classes, students are engaged in moderate to vigorous PA during $20 \%$ to $50 \%$ of the time ${ }^{18,28}$. In school class time about $30 \%$ of adolescents spend moderate to vigorous $\mathrm{PA}^{19}$.

In regard to recess time, a significant difference in the number of steps between HA and LA adolescents was observed but only for girls. It is important to emphasize that we are not aware of any study that has examined differences in PA during recess time between HA and LA adolescents. On the other hand, researches have been indicating that there is a difference between sexes in recess time. Mota, Silva, Santos, Ribeiro, Oliveira, Duarte ${ }^{29}$ showed that girls were more involved in moderate to vigorous PA during recess time than boys. While other studies indicated that boys were more active in recess time, compared to girls ${ }^{30-32}$. Therefore, our findings also highlight that school recess time is an important setting for promoting PA.

Our study has some limitations. First, the cross-sectional design impairs cause-effect inferences. Second, the use of pedometers does not allow measurement of PA intensity. Finally, the adolescents were not drawn in their respective classes, but the class as a whole. Despite these issues, a considerable strength of this investigation was the originality of research topic, as no study has examined the difference between PA levels in these contexts among Brazilian adolescents. As practical implications we highlight that parents, professors and school principals should develop strategies to promote a more active recess time, as well as PE classes structured with high intensity activities and to encourage active commuting to school.

\section{Conclusion}

HA girls are consistently more active in each domain analyzed compared to LA counterparts, while for boys PE class was the domain that differentiate the HA vs. LA adolescents. This study highlights some potential settings to be included in the policies focused in enhance PA levels among adolescents namely in the context of school PE.

\section{References}

1. Golden S, Williams J, Ford D, Yeh H, Sanford CP, Nieto F, et al. Depressive symptoms and the risk of type 2 diabetes: the atherosclerosis risk in communities study. Diabetes Care 2004; 27:429-35. Diabetes Care. 2004;27:429-35.

2. Katzmarzyk PT, Janssen I, Ardern C. Physical inactivity, excess adiposity and premature mortality. Obes Rev. 2003;4:257-90.

3. Luke A, Dugas L, Durazo-Arvizu R, Cao G, Cooper R. Assessing physical activity and its relationship to cardiovascular risk factors: NHANES 2003-2006. BMC Public Health. 2011;11(1):387.

4. Goodman E, Daniels S, Meigs J, Dolan L. Instability in the diagnosis of metabolic syndrome in adolescents. Circulation. 2007;115(17):2316-22.

5. Giulliano D, Christofaro D, Bo L, Maffei S, Andrade D, Virgílio $\mathrm{M}$, et al. Adolescents ' physical activity is associated with previous and current physical activity practice by their parents. J Pediatr. 2017;(xx):1-8. doi:10.1016/j.jped.2017.01.007

6. Masoumi HE. Associations of built environment and children's physical activity: a narrative review. Rev Environ Health. 2017;

7. Sallis JF, Cervero RB, Ascher W, Henderson KA, Kraft MK, Kerr J. an Ecological Approach To Creating Active Living Communities. Rev Public Heal. 2006;297-322.

8. Pate R, Davis M, Robins T, Stone E, McKenzie T, Young J. Promoting physical activity in children and youth: A leadership role for schools. Circulation. 2006;114:1214-24.

9. Gaya ACA, Garlipp DC, Silva MF, Moreira RB. Ciências do movimento humano. Introdução à metodologia da pesquisa. 1st ed. Porto Alegre: Artmed; 2008. 304 p.

10. Duncan M, Al-Nakeeb Y, Woodfield L, Lyons M. Pedometer determined physical activity levels in primary school children from central England. Prev Med. 2007;44(5):416-20.

11. Gabel L, Proudfoot N, Obeid J, MacDonald M, Bray S, Cairney J, et al. Step count targets corresponding to new physical activity guidelines for the early years. Med Sci Sport Exerc. 2013;45(2):314-8.

12. Tudor-locke C, Williams JE, Reis JP, Pluto D. Utility of Pedometers for Assessing Convergent Validity. Sport Med. 2002;32(12):795-808.

13. C Tudor-Locke, Pangrazi R, Corbin C, Rutherford W, Vincent $\mathrm{S}$, Raustorp A, et al. BMI-referenced standards for recommended pedometer-determined steps/day in children. Prev Med. 2004;38(6):857-64.

14. Sallis JF, Bull F, Guthold R, Heath GW, Inoue S, Kelly P, et al. Series Physical Activity 2016 : Progress and Challenges Progress in physical activity over the Olympic quadrennium. Lancet. 2016;6736(16):1-12. 
15. Hallal PC, Andersen LB, Bull FC, Guthold R, Haskell W, Ekelund U, et al. Global physical activity levels: Surveillance progress, pitfalls, and prospects. Lancet. 2012;380(9838):247-57.

16. Rosa CS da C, Messias KP, Fernandes RA, Silva CB da, Monteiro HL, Júnior IFF. Atividade física habitual de crianças e adolescentes mensurada por pedômetro e sua relação com índices nutricionais. Rev Bras Cineantropom Desempenho Hum. 2011;13(1):22-8.

17. Wong BY-M, Faulkner G, Buliung R. GIS measured environmental correlates of active school transport: A systematic review of 14 studies. Int J Behav Nutr Phys Act. 2011;8.

18. Smith MP, Berdel D, Nowak D, Heinrich J. Physical Activity Levels and Domains Assessed by Accelerometry in German Adolescents from GINIplus and LISAplus. PlosOne. 2016;1-17.

19. Pizarro AN, Schipperijn J, Ribeiro JC, Figueiredo A, Mota J, Santos MP. Gender Differences in the Domain-Specific Contributions to Moderate-to-Vigorous Physical Activity, Accessed by GPS. Hum Kinet. 2017;14(6):474-8.

20. Østergaard L, Kolle E, Steene-johannessen J, Anderssen SA, Andersen LB. Cross sectional analysis of the association between mode of school transportation and physical fitness in children and adolescents. 2013;1-7.

21. Pinto A de A, Claumann GS, Angelo HCC de, Menezes EC, Dias DT, Pelegrini A. active commuting to school and associated factors among adolescents: a systematic review. J Phys Educ. 2017;28(e2859):1-11.

22. Ramírez-vélez R, García-hermoso A, Agostinis-sobrinho C, Mota J, Santos R, Correa-bautista JE, et al. Cycling to School and Body Composition, Physical Fitness, and Metabolic Syndrome in Children and Adolescents. J Pediatr. 2015;188:57-63.

23. Larouche R, Saunders TJ, Faulkner GEJ, Colley R, Tremblay M. Associations between active school transport and physical activity, body composition, and cardiovascular fitness: a systematic review of 68 studies. J Phys Act Heal. 2014;11(1):206-27.

24. Lemes VB, Brand C, Dias A, Moreira R, Gaya A, Gaya A. Preferências De Atividade Física E Esportes Para Escolares No Ensino Fundamental. Rev Kines. 2016;34:3-16.

25. Bento GG, Ferreira E, Silva FC da, Mattana PH, Silva R da. Motivação para a prática de atividades físicas e esportivas de crianças : uma revisão sistemática. Rev Bras Atividade Física Saúde. 2017;22(1):13-23.

26. Sallis J, McKenzie T, Beets M, Beighle A, Erwin H, Lee S. Physical education's role in public health: steps forward and backward over 20 years and HOPE for the future. Res Q Exerc Sport. 2012;83(2):125-35.
27. Alderman BL, Benham-deal T, Beighle A, Erwin HE, Olson RL. Physical Education's Contribution to Daily Physical Activity Among Middle School Youth. Pediatr Exerc Sci. 2012;24:634-48.

28. Smith NJ, Lounsbery MAF, Mckenzie TL. Physical Activity in High School Physical Education : Impact of Lesson Context and Class Gender Composition. J ot Phys Act Heal. 2014;11:127-35.

29. Mota J, Silva P, Santos M, Ribeiro J, Oliveira J, Duarte J. Physical activity and school recess time: Differences between the sexes and the relationship between children's playground physical activity and habitual physical activity. J Sports Sci. 2005;23(3):269-75.

30. Greca J, Silva D. Sedentary Behavior During School Recess in Southern Brazil. Percept Mot Ski. 2016;

31. Viciana J, Mayorga-vega D, Martfnez-baena A. Moderate-toVigorous Physical Activity Levels in Physical Education, School Recess, and After-School Time: Influence of Gender, Age, and Weight Status. 2016;1117-23.

32. Martinez-gomez D, Veiga OL, Zapatera B, Gomez-martinez S, Martínez D, Marcos A. Physical Activity During High School Recess in Spanish Adolescents : The AFINOS Study. 2014;1194-201.

\section{Acknowledgement}

This work was supported scholarship from Brazilian government by CAPES (Coordination for the Improvement of Higher Level) and CNPq (National Council for Scientific and Technological Development).

\section{Corresponding author}

Arieli Fernandes Dias

Street: Felizardo, 750. Neighborhood: Jardim botânico. 90690-200

City: Porto Alegre, Brazil.

E-mail: ariieli_dias@hotmail.com

Manuscript received on May 28, 2018

Manuscript accepted on September 15, 2018

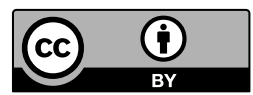

Motriz. The Journal of Physical Education. UNESP. Rio Claro, SP, Brazil - eISSN: 1980-6574 - under a license Creative Commons - Version 3.0 